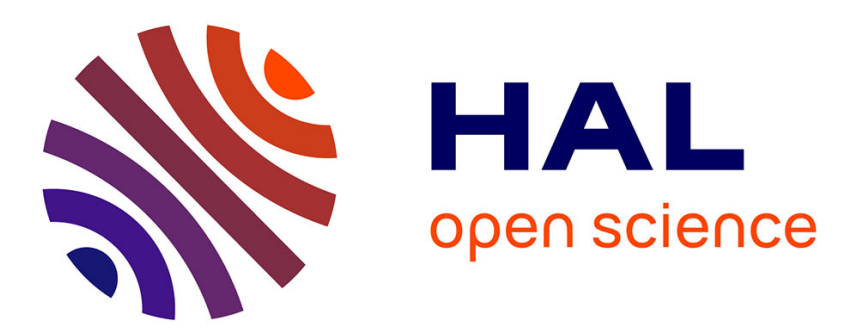

\title{
Agricultural Applications for Electromagnetic Exposure
} Hadi Aliakbarian, Amin Enayati, Hossein Ameri Mahabadi, Maryam Ashayer Soltani

\section{To cite this version:}

Hadi Aliakbarian, Amin Enayati, Hossein Ameri Mahabadi, Maryam Ashayer Soltani. Agricultural Applications for Electromagnetic Exposure. Asia-Pacific Microwave Conference, 2007 (APMC 2007), Dec 2007, Thailand. pp.1-4. hal-00716755

\section{HAL Id: hal-00716755 https://hal.science/hal-00716755}

Submitted on 5 Aug 2012

HAL is a multi-disciplinary open access archive for the deposit and dissemination of scientific research documents, whether they are published or not. The documents may come from teaching and research institutions in France or abroad, or from public or private research centers.
L'archive ouverte pluridisciplinaire HAL, est destinée au dépôt et à la diffusion de documents scientifiques de niveau recherche, publiés ou non, émanant des établissements d'enseignement et de recherche français ou étrangers, des laboratoires publics ou privés. 


\title{
Agricultural Applications for Electromagnetic Exposure
}

\author{
Hadi Aliakbarian ${ }^{1,2}$, IEEE Student Member, Amin Enayati ${ }^{1,2}$, Hossein Ameri ${ }^{2}$,IEEE Member, \\ Maryam Ashayer Soltani ${ }^{3}$
}

\author{
h.aliakbarian@ieee.org, amin.enayati@gmail.com,itmmwave@streamyx.com, itmmwave@streamyx.com \\ ${ }^{1}$ School of ECE, Univ. of Tehran, P.O.Box: 14395-514. \\ ${ }^{2} I T \& m m$ waves. SDN. BHD (Malaysia) (phone: $\left.+60-132347579\right) ;{ }^{3}$ IBS, Universiti Teknologi Malaysia (UTM)
}

\begin{abstract}
Despite the advances in bug controlling and antifreezing operations of agricultural products, the devastation of Sunne pests and freezing is still enormous. Traditional treatments such as chemical insecticides for bug controlling and covering to avoid freezing have not been sufficient. In the presented paper, new ideas of using electromagnetic treatment for anti-freezing operation, pre-harvest Sunne pest control, and Orchid flower control are introduced.
\end{abstract}

keywords- Electromagnetic Exposure, Pest Control, AntiFreezing. Thrips, Sunne pest, wheat, Orchid flower, pistachio

\section{INTRODUCTION}

Is NTERACTIVE relations between various branches of science and technology have improved interdisciplinary fields. In fact, most of the research options take place in some places among these branches. Therefore, a specialist from one branch usually can propose novel methods, whenever enters the new field, based on his previous knowledge. In this brief paper, three of new ideas from electromagnetism to be used in agriculture are introduced. With the growth in the world population especially in thirdworld countries, the need to agricultural products including fruits and corns is drastically increasing. Although the production of these important foodstuffs is increased, the challenges of freezing due to temperature decrement and pests control are still unsolvable in many aspects.

In this paper, two upgraded methods for pest controlling and anti-freezing operations based on electromagnetic exposure are investigated. In section 2 , the idea of using electromagnetic waves to avoid products from freezing is discussed. In section 3, based on previous work of the group [1-5], this idea is extended to control of Sunne-pest, which is one of the most harmful bugs in the Middle Eastern region. In section 4, the problem of Orchid pest is introduced and in section 5 , it is discussed that how to warm up a material selectively. In section 6 , some upcoming challenges are introduced and finally the paper is concluded in section 7 .

\section{Electromagnetic Waves to Protect Agricultural PRODUCTS FROM FREEZING}

One of the major problems in the agricultural products the world and also in Iran is the problem of fruits and agricultural products freezing in unexpected cold days of the year. In many areas, reduction of temperature in a few days, while the product hasn't been grown completely, may cause huge economic injuries. These detriments will be more painful when occur for costly productions like pistachio and citruses. By the end of winter, at the beginning of spring, plants are about to flourish. Because of the fact that the weather is not stable, the temperature may fall all of a sudden. Therefore, the biological tissues of the budded pistachio or other products may be damaged. It has been found that if the temperature of the production is increased about two or three degrees, we can save them from being offended immensely. The proposed idea is to warm up the pistachio remotely and selectively using electromagnetic exposure while the other materials of the environment are not warmed up. The most significant work is to find the best frequency in which the absorption rate of energy in pistachio and sensitive objects is the most. This frequency depends on the electromagnetic characteristics of the objects and can be measured practically.

The previous techniques of anti-freezing have been limited to chemical, biophysical and genetic treatments. They are more expensive and hard to exploit than the mentioned solution. More over, they have some potential hazards for consumers. Additionally, they need much time than they can be exploited on demand when the weather gets colder. We must estimate the weather condition far before necessity while, with the use of electromagnetic waves, it is no need to exact weather condition prediction. Regarding to these advantages, it seems that this method can find a suitable place among the other methods in anti-freezing application.

The idea is based on a characteristic of material called permittivity. Each material, related to its molecular structure, 
has a permittivity showing how an electromagnetic wave propagates in it. The imaginary part of the permittivity is responsible for the absorption of the energy in the material, and consequently, warming up the environment. Moreover, this characteristic highly depends on the applied frequency. Finding the best frequency for a material to be warm up, we can warm up the pre-harvest products remotely by exposing the electromagnetic wave in the field. We have done some primary simulations using approximate parameters. Figures 1 and 2 show an HFSS model of a pistachio branch and the volume loss density caused by an incident electromagnetic wave respectively

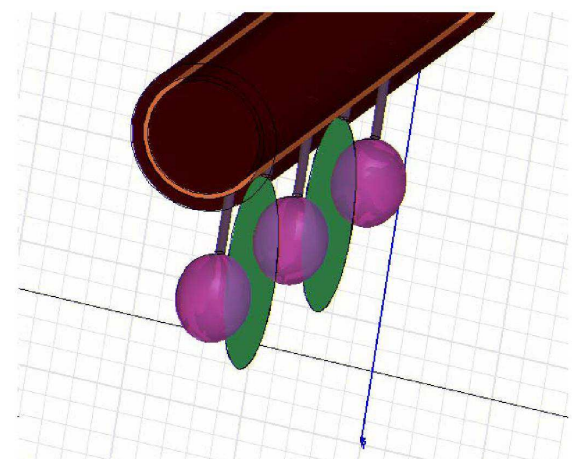

Figure.1: Pistachio branch model

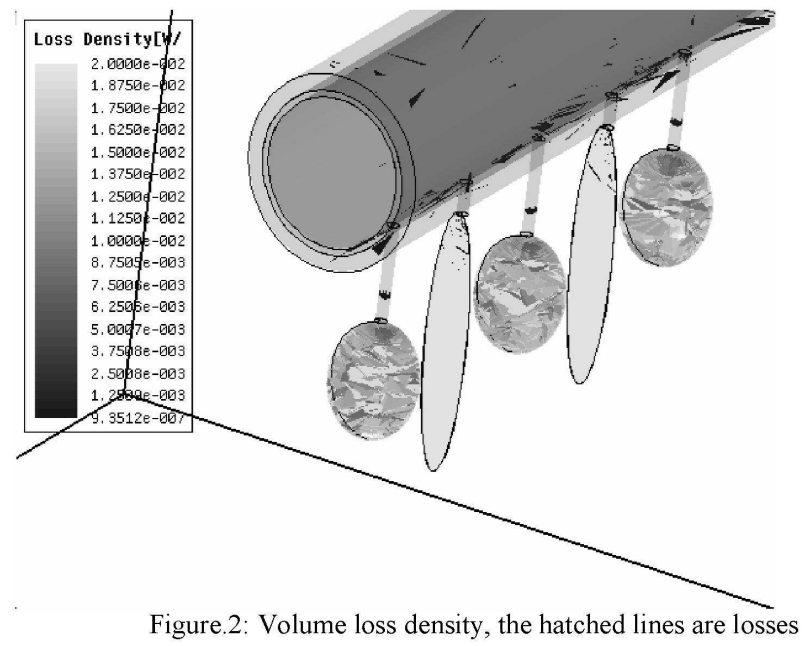

The idea is going to be case studied and implemented in Iran for the fields of pistachio in Rafsanjan shown in Figure 3 experimentally. In addition, evaluation of other aspects of the project, such as economical considerations and environmental effects will be regarded.

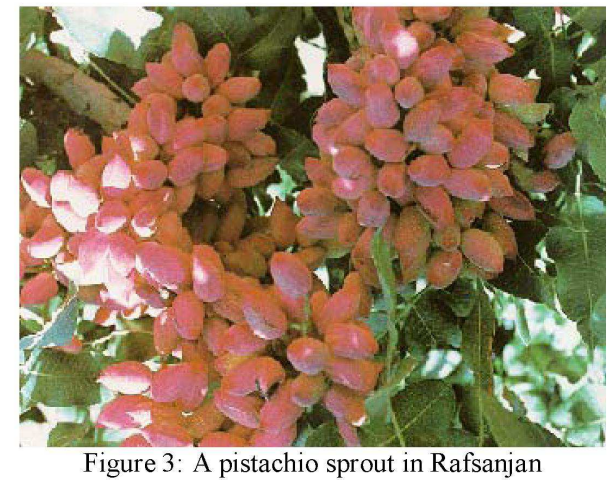

\section{SunNe Pest Control of Wheat}

Sunne pest or 'Eurygaster integriceps', shown in Figure 4 (a)-(b), is the most destroying sap-sucking bug of wheat in Iran, middle east, central and east Europe and North Africa in about twenty countries. It is said that the most injures in wheat production in these regions is due to this pest. The extent of damage caused and the difficult terrain where it is traditionally found have forced governments to do a lot of investment to control them but it is not appropriately worked out at least in Iran and in our neighbors. However, a vast part of the agricultural researches belong to this issue. All of the successes in Iranian researches were in chemical fertilizers and it is obvious that there is a lot of criticisms in to use these fertilizers.

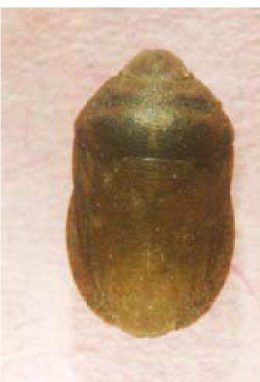

(a)

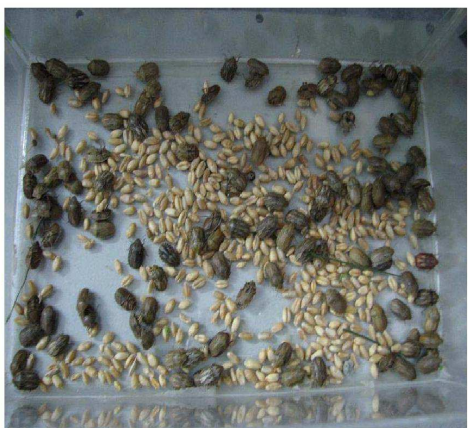

(c)

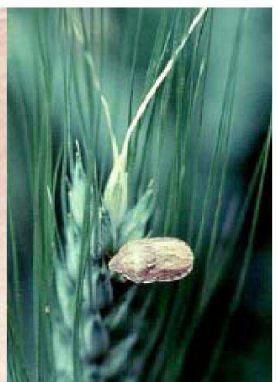

(b)

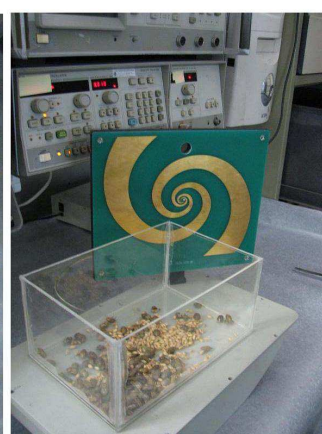

(d)
Figure 4: (a) A typical Sunne pest (b) A Sunne pest sucking (c) Sunne samples in the box wheat (d) Sunne samples under exposure

Traditional farmers usually use simpler chemical sprayers to control bugs. Despite the simplicity of use, these chemical insecticides have many disadvantages such as reducing the 
thickness of Ozone layer [6]. As a result, some modern techniques such as genetic treatments and some other unconventional methods such as ultrasonic waves and electromagnetic treatments have been suggested. Formerly, the third method has been suggested for pest control of postharvest stored products such as Rice, fruits and walnuts [6-14]. Here the idea of using electromagnetic exposure to control Sunne pest in winters before their migration and attack to wheat farms has been discussed. This method is based on interfering the biological organization of Sunne pests. Similar treatments may be applied to other kinds of pests.

The lifetime of the Sunne pests is only one year. By the end of March, groups of Sunne pests start to migrate to wheat farms and hurt their widest harm to flourishing wheat in 15 to 30 days. Also they start reproducing and then they come back to mountains until the next year. Furthermore, they have a winter sleep when they are in mountains and use their stored energy until the next year. Sunne pest can fly about 30 kilometers to the farms and so all of their winter shelters are known and are smaller than wheat farms. Traditional method of spraying poison to kill them in the winter is unsuccessful because they take crucibles as their shelters during these days. Therefore we should seek another method to treat them in this season. Sunne pests like many other insects are too sensitive to temperature variations and hence they don't attack to Khoozestan farms in south of Iran which is a warm land. In addition, Sunne pests are more sensitive to temperature variations in the period of sleep in winter and the variation of climate temperature in this period usually causes an immense damage on them. The reason is that they have diapause phenomena in this time which don't allow them to reproduce and nourish, so it makes them resist against coldness in order to save their energy during winter. As a consequence, if we can heat up them to about 12 to 15 degrees they will wake up and their diapause will be broken. Consequently they should fly, reproduce, and move but not eat because they don't have any food. These activities result in shedding their energy with impunity and probably they can't live until spring or if they can, they can't fly to wheat farms due to the lack of energy. If this heating up is exposed more, their lives will be threatened seriously. In section IV, the idea of using electromagnetic exposure to warm up pests or products is explained. Figure 4 (c)-(d), represents some of our practical tests on Sunne pest samples to find suitable frequencies of electromagnetic exposure. The electromagnetic post-harvest treatment can also be done in silos to control post-harvest pests [12]. More investigation are in progress.

\section{BUG CONTROL OF ORCHID FLOWERS}

Orchid, shown in Figure 5 (a), is one of the most important flowers in Malaysia. Unfortunately, several pests such as Aphids, red spider mites and thrips, shown in Figure 5 (b), attack orchids; therefore it is essential to protect them against harmful damages. We suggest using electromagnetic exposure to prevent pests from coming near buds. The method is similar to the above treatment which is based on remote warming of pests using electromagnetic exposure. Moreover, it is possible to find a frequency at which a bug is sensitive due to its biological system but there is no considerable heating.

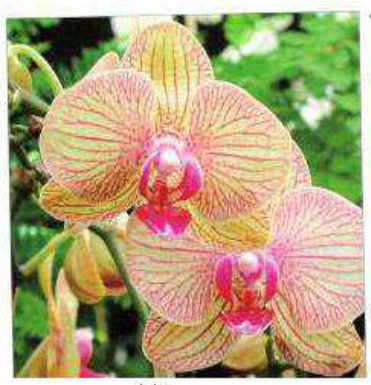

(a)

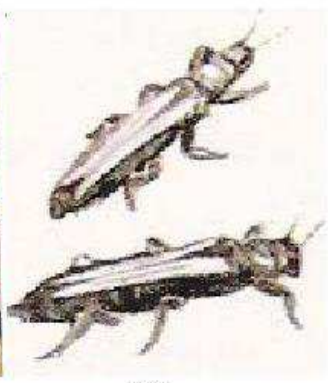

(b)
Figure 5: (a) a typical orchid (b) harmful thrips

\section{Electromagnetic HeAting}

Each material has a complex permittivity $(\varepsilon)$ in general. According to measurements, usually this value is noticeably frequency dependent. The imaginary part $\left(\varepsilon^{\prime \prime}\right)$ of this value is responsible for absorption of electromagnetic Waves in each material. Eq.1 shows the general form of the first Maxwell's equation considering $\left(\varepsilon^{\prime \prime}\right)$.

$$
\begin{aligned}
\nabla \times H= & j \omega \varepsilon^{\prime} E+J=j \omega \varepsilon^{\prime} E+\sigma E \\
& =j \omega\left(\varepsilon^{\prime}-j \frac{\sigma}{\omega}\right) E=j \omega\left(\varepsilon^{\prime}+\varepsilon^{\prime}\right) E
\end{aligned}
$$

As a consequence, total power absorption in a specific material is achieved if the second part of the equation is integrated over the material volume as can be seen in Eq.2.

$$
P_{\text {Loss }}=\int_{v} E J d V=\int_{v} \sigma|E|^{2} d V=\omega \int_{v} \varepsilon^{\prime \prime}|E|^{2} d V
$$

The basic idea is to use $\varepsilon^{\prime \prime}$ to warm the selected materials far from electromagnetic source. Using the absorption frequency of water in $2.4 \mathrm{GHz}$ may help us in warming the water in their body but probably all of the other plants, animals and insects near there absorb the energy. Thus it is decided to find another frequency to expose the electromagnetic energy. In order to do this, we measured the Sunne pest effective permittivity to find the best frequency in which the difference between $\varepsilon^{\prime \prime}$ of the pest and other materials like crucibles in the environment is the largest.

\section{Challenging Problems}

There are six challenging problems against the implementation of these ideas: power, health effects, biological effects, price, frequency allocation and design. Power problem is solvable if the employed frequency is not higher than gigahertz. High power sources are now common in VHF and UHF frequencies and this problem is solvable paying reasonable money.

Today, electromagnetic wave is known as a potential hazard of health and biological effects such as cancer, but it is reported that lowering the exposure time will reduce the hazard. Thus in our method we expose the waves for limited 
periods which is enough to increase the temperature of Sunne pests or products. Moreover, Sunne pest shelters are usually empty of human population. In spite of the health effect, biological effects of electromagnetic exposure should be evaluated to ensure that it does not have a harmful effect on the ecosystem.

The problem of price is also an economic topic that should be considered by investors. The enormous detriments of Sunne pest may motivate large companies in this investment. The problem of frequency allocation could be solved in Iran as well. Taking few frequencies to send career in probably VHF and for limited days in year is not unachievable, however we can shift our frequency to ISM bands.

The final field problem is to design such a plan to warm up pests in different areas. For example if we use a single power source, it will be difficult to use it for a wide uneven area. Thus for each area, this problem should be solved separately and one should design a suitable array of sources to cover the area. Additionally the frequency of treatment must be selected in a manner that the absorption of energy by pest be more than other materials.

\section{CONCLUSION}

In the presented paper, we discussed three problems in agriculture which are freezing problem for pistachio and pest controlling for wheat and Orchid. In this way, the exploitation of electromagnetic fields to face these challenges has been presented and some upcoming challenges toward the implementation of these ideas have been evaluated. It seems that this method worth to be mentioned more and to be upgraded.

\section{REFERENCES}

[1] H. Aliakbarian, A. Enayati, S. Farsi, H. Ajam, H. Ameri, and M. Ashayer Soltani, "Pre-harvest Annihilation of Sunne-Pest in Winters Using Electromagnetic Exposure", Proc. ICCEA, IEEE, 2004, pp.446448.

[2] H. Ameri, M. Ashayer Soltani, F.Ramazani_nia "Challenging of agricultural pest by Electromagnet waves (seminar)"; 7 Dec. 2003, Agricultural Research Center (Karadj), Iran.

[3] H.Ameri, M.Ashayer Soltani "Application of Electromagnetic Waves in Agricultural (seminar);, 20-22 Oct. 2003, University of Saveh, Saveh, Iran.

[4] H.Ameri, M.Ashayer Soltani "Application of Microwave for Control of Sunne Pest (seminar)", 26 April 2004, Sunne Pest Research Center, (Varamin), Iran.

[5] H.Ameri, M.Ashayer Soltani "Modeling of Grain's Pest (seminar)";, 21 Dec. 2003, University of Tabriz, Tabriz, Iran.

[6] J. Tang, S. Wang, J. Hansen, J. Johnson, E. Mitcham, S. Drake, and G. Hallman, "Postharvest Control of Insect Pests in Nuts and Fruits Based on Radio Frequency Energy"; ISHS Acta Horticultura, 2003, ISSU 599, pp. $175-182$.

[7] P. Kunstadt, "Radiation Disinfestations and Fumigant Replacement, A Technology Whose Time Is Now", The International Research Conf. on Methyl Bromide Alternatives \& Emissions Reductions, 1999.

[8] H. Frings", "Factors determining the effects of radio-frequency electromagnetic fields on insects and materials they infest", J. Econ. Entomol., vol.45(3), pp. 396, 1952.

[9] S.O. Nelson, and L. E. tetson; "Possibilities for Controlling Insects with Microwaves and Lower Frequency RF Energy", IEEE Trans. on MTT, vol. 22, Dec 1974, pp. $1303-1305$.
[10] Nelson, S.O.; "Review and assessment of radio-frequency and microwave energy for stored-grain insect control", Trans. ASAE, vol. 39, pp.1475-1484, 1996.

[11] S. Wang, J. Tang, J.A. Johnson, E. Mitcham, J.D. Hansen, R.P. Cavalieri, J. Bower, and B. Biasi; "Process protocols based on radio frequency energy to control field and storage pests in in-shell walnuts", Postharvest Biology And Technology, May 20, 2002.

[12] S. L. Halverson, T. S. Bigelow, and K Lieber "Penetration of Infested Stored-Products by EHF/SHF Microwave Energy"; Annual Intern. Research Conf. on Methyl Bromide Alternatives and Emissions Reductions, 1998.

[13] S. Wang, J. Tang, "Radio Frequency and Microwave Alternative Treatments for Insect Control in Nuts: A Review"; Agricultural Engineering Journal, vol. 10 (3\&4), pp.105-120, 2001.

[14] S. Wang, J Tang, J. A. Johnson, E Mitcham, J. D. Hansen, G. Hallman, S. R. Drake, Y. Wang, "Dielectric Properties of Fruits and Insect Pests as related to Radio Frequency and Microwave Treatments"; Bio-systems Engineering Journal, pp.:201-212, April, 2003. 